\title{
Development and validation of a novel competing risk model for predicting survival of esophagogastric junction adenocarcinoma: a SEER population-based study and external validation
}

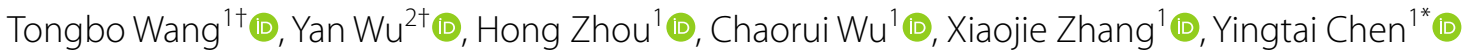
and Dongbing Zhao ${ }^{1 *}$ (1)

\begin{abstract}
Background: Adenocarcinoma in Esophagogastric Junction (AEG) is a severe gastrointestinal malignancy with a unique clinicopathological feature. Hence, we aimed to develop a competing risk nomogram for predicting survival for AEG patients and compared it with new 8th traditional tumor-node-metastasis (TNM) staging system.

Methods: Based on data from the Surveillance, Epidemiology, and End Results (SEER) database of AEG patients between 2004 and 2010, we used univariate and multivariate analysis to filter clinical factors and then built a competing risk nomogram to predict AEG cause-specific survival. We then measured the clinical accuracy by comparing them to the 8th TNM stage with a Receiver Operating Characteristic (ROC) curve, Brier score, and Decision Curve Analysis (DCA). External validation was performed in 273 patients from China National Cancer Center.

Results: A total of 1755 patients were included in this study. The nomogram was based on five variables: Number of examined lymph nodes, grade, invasion, metastatic LNs, and age. The results of the nomogram was greater than traditional TNM staging with ROC curve (1-year AUC: 0.747 vs. 0.641, 3-year AUC: 0.761 vs. 0.679, 5-year AUC: 0.759 vs. 0.682 , 7-year AUC: 0.749 vs. $0.673, P<0.001$ ), Brier score (3-year: 0.198 vs. $0.217, P=0.012 ; 5$-year: 0.198 vs. $0.216, P=0.008$; 7-year: 0.199 vs. $0.215, P=0.014$ ) and DCA. In external validation, the nomogram also showed better diagnostic value than traditional TNM staging and great prediction accuracy.
\end{abstract}

Conclusion: We developed and validated a novel nomogram and risk stratification system integrating clinicopathological characteristics for AEG patients. The model showed superior prediction ability for AEG patients than traditional TNM classification.

\footnotetext{
*Correspondence: yingtaichen@126.com; dbzhao@cicams.ac.cn

†Tongbo Wang and Yan Wu contributed equally to this work

1 Department of Pancreatic and Gastric Surgical Oncology, National

Cancer Center/National Clinical Research Center for Cancer/

Cancer Hospital, Chinese Academy of Medical Sciences and Peking

Union Medical College, No. 17 PanjiayuanNanli, Chaoyang District,

Beijing 100021, China

Full list of author information is available at the end of the article
}

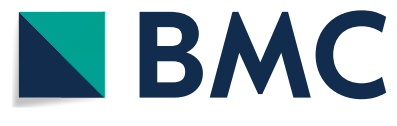

(c) The Author(s) 2021. Open Access This article is licensed under a Creative Commons Attribution 4.0 International License, which permits use, sharing, adaptation, distribution and reproduction in any medium or format, as long as you give appropriate credit to the original author(s) and the source, provide a link to the Creative Commons licence, and indicate if changes were made. The images or other third party material in this article are included in the article's Creative Commons licence, unless indicated otherwise in a credit line to the material. If material is not included in the article's Creative Commons licence and your intended use is not permitted by statutory regulation or exceeds the permitted use, you will need to obtain permission directly from the copyright holder. To view a copy of this licence, visit http://creativecommons.org/licenses/by/4.0/. The Creative Commons Public Domain Dedication waiver (http://creativeco mmons.org/publicdomain/zero/1.0/) applies to the data made available in this article, unless otherwise stated in a credit line to the data. 
Keywords: Esophagogastric junction adenocarcinoma, Nomogram, Competing risk analysis, SEER database

\section{Background}

Despite the incidence trend continuously decreased over the past few decades, gastric cancer remains the fifth most common malignant tumor and ranks third in cancer-related mortality in the world [1, 2]. An growing number of population-based studies had observed that the incidence of adenocarcinoma in the esophagogastric junction (AEG) presenting a significantly rising tendency [3-5]. According to the latest 8th edition of the American Joint Committee on Cancer (AJCC) Cancer Staging Manual, the Tumor-Node-Metastasis (TNM) staging system of AEG had been divided due to its unique clinicopathological characteristicsl: viz. tumors with their epicenter within the proximal $2 \mathrm{~cm}$ of the esophagogastric junction (EGJ) invaded (Siewert I/II) are classified as the version of TNM-esophagus cancer, and tumors with their epicenter more than $2 \mathrm{~cm}$ distal from the EGJ would be classified as TNM-gastric cancer [6]. However, this staging strategy for AEG only focused on the 'location' of invasion, neglecting other critical clinical features, such as age, sex and the number of resected lymph node (LN), which could be predicting factors that influencing patients' prognosis [7-10]. Thus, the prognostic evaluation system for AEG needs to be further explored.

In general, the survival of cancer patients may be affected by more than two events, and only one event occurs finally [11]. Those events other than the one of interest are called competing risk events. The traditional survival analysis may overestimate the cumulative incidence by treating competing events as censored events, which could be improved by the competing risk analysis. Nomogram, a simple graphical linear prediction model, is widely used for cancer prognosis [12]. Hence, in this study, we aimed to explore a new classification system by competing risk model through the population-based Surveillance, Epidemiology and End Results (SEER) database and further develop and externally validate a nomogram for predicting survival for AEG patients.

\section{Methods}

\section{Training cohort and data acquisition}

Patient data were obtained from the SEER website (http://seer.cancer.gov/) using SEER*stat version 8.3.5. In total, data from 2004 to 2010 of 11,639 esophagogastric junction (EGJ) cancer patients over 18 years old were initially analyzed. The inclusion criteria were as followed: (1) patients with histological confirmed adenocarcinomas in EGJ; (2) patients who received surgery and complete pathological information can be achieved; (3) without distant metastasis; The exclusion criteria were as followed: (1) patients with multiple primary tumors; (2) primary EGJ cancers with other histology; (3) primary EGJ adenocarcinomas without histological confirmation; (4) patients with distant metastasis; (5) patients without complete pathological information; (6) patients with follow-up time less than 3 months. Finally, we extracted clinicopathological variables of 1755 patients including age, gender, race, location of the tumor, TNM staging, the grade of the tumor, histological grade, number of examined LNs, number of positive LNs, tumor size, and survival months.

\section{External validation cohort and data}

To further validate our new predicting model, we sought an external validation cohort from patients diagnosed from October 2006 to December 2018 and underwent radical resection in China National Cancer Center. The validation cohort included 273 AEG patients who were recruited according to inclusion and exclusion criteria same as the training cohort. The time of last follow-up was March 2019. All study procedures were approved by the Institutional Review Board at the China National Cancer Center.

\section{Exploration of a new evaluation system and presentation of nomograms}

We regarded AEG cause-specific death and other causes of death as two competing events in our competing-risk analysis. The multivariate proportional sub-distribution hazard model was used to calculate the adjusted sub-distribution hazard ratio (SHR) of the new examined evaluation system. Variables associated with AEG cause-specific death with a $P$ value of $<0.1$ in the univariate analysis, or a $P$ value of $<0.05$ in the initial multivariate analysis, were included as variables in the final multivariate analysis. We not only built the proportional sub-distribution hazard model to predict cause-specific death for patients, but also competing-risk nomograms based on Fine and Gray's model [13]. For comparing the predicted probability with points observed at a certain time, a calibration plot was used. If both the predicted and observed probabilities in any given pair lie on the $45^{\circ}$ line, it implies that both probabilities match well to each other and the model is ideal. The discrimination of the model was assessed by areas under receiver operating characteristic curves (AUC) [14]. If the AUC $>0.8$, it 
indicates that the discriminatory accuracy of a model is good. The discrimination and calibration of the model were also measured by the Brier score at the same time [15]. The decision curve analysis (DCA) was then used to estimate the clinical usefulness and net benefit of the predictive models, as well as compare them with the traditional TNM staging system of the training cohort [16, 17]. This method was capable to visualizes the clinical consequences of a treatment strategy at each threshold probability.

\section{Statistical analysis}

All statistical analyses were performed using $\mathrm{R}$ software, version 3.3.3 (Institute for Statistics and Mathematics, Vienna, Austria; http://www.r-project.org). Statistical significance was set at two-sided $P<0.05$.

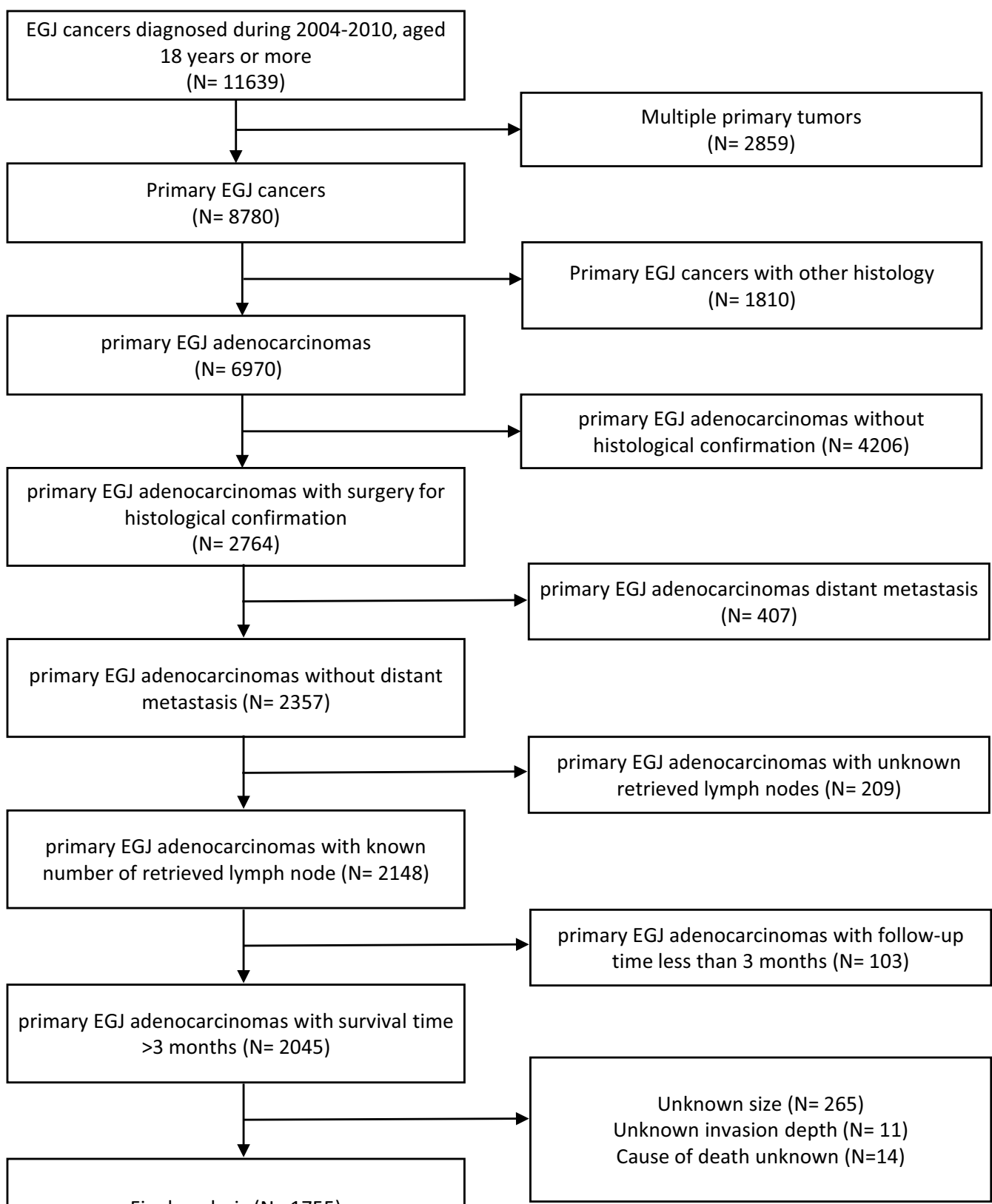

Fig. 1 Flowchart of the training cohort patients selection for this study 
Table 1 Characteristics of two cohorts of patients with AEG

\begin{tabular}{lllll}
\hline Characteristics & $\begin{array}{l}\text { Training cohort } \\
(\mathrm{N}=1755)\end{array}$ & & $\begin{array}{l}\text { Validation cohort } \\
(\mathrm{N}=273)\end{array}$ \\
\cline { 2 - 2 } & No. of patients $\%$ & & No. of patients $\quad \%$
\end{tabular}

\begin{tabular}{|c|c|c|c|c|}
\hline \multicolumn{5}{|l|}{ Race } \\
\hline White & 1523 & 86.8 & 0 & 0 \\
\hline Black & 81 & 4.6 & 0 & 0 \\
\hline Others & 151 & 8.6 & 273 & 100 \\
\hline \multicolumn{5}{|l|}{ Sex } \\
\hline Female & 373 & 21.2 & 73 & 26.7 \\
\hline Male & 1382 & 78.8 & 200 & 73.3 \\
\hline \multicolumn{5}{|l|}{ Age (year) } \\
\hline$<60$ & 674 & 38.4 & 154 & 56.4 \\
\hline$\geq 60$ & 1081 & 61.6 & 119 & 43.6 \\
\hline \multicolumn{5}{|l|}{ Grade } \\
\hline Low grade & 946 & 53.9 & 223 & 81.6 \\
\hline High grade & 809 & 46.1 & 50 & 18.4 \\
\hline \multicolumn{5}{|l|}{ T stage } \\
\hline $\mathrm{T} 1$ & 355 & 20.2 & 47 & 17.2 \\
\hline $\mathrm{T} 2$ & 227 & 12.9 & 38 & 13.9 \\
\hline T3 & 768 & 43.8 & 63 & 23.1 \\
\hline $\mathrm{T} 4$ & 405 & 23.1 & 125 & 45.8 \\
\hline \multicolumn{5}{|l|}{ N stage } \\
\hline No & 716 & 40.8 & 25 & 9.2 \\
\hline $\mathrm{N} 1$ & 391 & 22.2 & 46 & 16.8 \\
\hline N2 & 340 & 19.4 & 68 & 24.9 \\
\hline N3 & 308 & 17.6 & 134 & 49.1 \\
\hline \multicolumn{5}{|l|}{ Size (cm) } \\
\hline$<1.0$ & 83 & 4.7 & 8 & 2.9 \\
\hline$<2.0$ & 189 & 10.8 & 42 & 15.4 \\
\hline$<3.0$ & 265 & 15.1 & 49 & 17.9 \\
\hline$<5.0$ & 584 & 33.3 & 102 & 37.4 \\
\hline$\geq 5.0$ & 634 & 36.1 & 72 & 26.4 \\
\hline \multicolumn{5}{|c|}{ Number of examined lymph nodes } \\
\hline$<5$ & 128 & 7.3 & 3 & 1.1 \\
\hline$<10$ & 323 & 18.4 & 5 & 1.8 \\
\hline$<15$ & 428 & 24.4 & 20 & 7.3 \\
\hline$\geq 15$ & 876 & 49.9 & 245 & 89.7 \\
\hline $\begin{array}{l}\text { Follow-up time } \\
\text { (months, median, } \\
\text { lQR) }\end{array}$ & $33(14,79)$ & & $21(12-40)$ & \\
\hline
\end{tabular}

IQR interquartile range

\section{Results}

\section{Patients characteristics}

In total, 11,639 adults were diagnosed with EGJ cancer from 2004 to 2010, 2859 of which were excluded due to having multiple primary tumors. Furthermore, patients with other histology $(\mathrm{N}=1810)$ except adenocarcinoma, without histological confirmation $(\mathrm{N}=4206)$, with distant metastasis $(\mathrm{N}=407)$, or with unknown examined LNs $(\mathrm{N}=209)$ were also excluded. In addition, primary AEG with a follow-up of less than 3 months $(\mathrm{N}=103)$, unknown size $(\mathrm{N}=265)$, unknown invasion depth $(\mathrm{N}=11)$, or cause of unknown death $(\mathrm{N}=14)$ were excluded as well. In the end, 1755 cases were included in further analysis (Fig. 1), comprising 373 females (21.2\%) and 1382 males (78.8\%), with sixty years being used as a cut-off for elderly people. The T stage ranged from $\mathrm{T} 1$ to $\mathrm{T} 4$ ( $\mathrm{N}=355,227,768,405$, respectively), and the $\mathrm{N}$ stage from N0 to $\mathrm{N} 3(\mathrm{~N}=716,391,340,308$, respectively). The external validation cohort comprised 73 females (26.7\%) and 200 males $(73.3 \%)$, with $81.6 \%$ low grade and $18.4 \%$ high grade differentiation. The details of the baseline characteristics of participants of two cohorts are shown in Table 1.

\section{AEG survival prediction model}

In the final multivariate proportional sub-distribution hazard model of clinical characteristics for the prognosis of AEG in the training cohort, an age of $>60$ years (SHR 1.389, $P<0.001$ ), high T stage (T1-4, SHR 1.592, 2.167, 2.555 , respectively, $P<0.001)$, high $\mathrm{N}$ stage $(\mathrm{N} 0-3$, SHR $1.814,2.505,3.335, P<0.001$ ), or high Grade (SHR 1.281, $P<0.001)$ was associated with a poor prognosis, while the number of examined LNs presented to be a protective factor $(<10,<15, \geq 15$, SHR 0.751, 0.635, 0.540, $P<0.001)$. The results of multivariate analysis are listed in detail in Table 2.

\section{Construction of the competing risk nomogram}

The AEG cause-specific death predicting model of the nomogram was established based on a selection of prognostic factors (Fig. 2). The nomogram showed the $\mathrm{N}$ stage to be the most impactful factor of prognosis, followed by the $\mathrm{T}$ stage, and then age, with the amount of examined LNs and grade having only a modest effect on survival. Each subtype of the variables was assigned a score. A straight line to determine the estimated probability of survival can be drawn at each time point on the total point scale, according to the total point.

\section{Evaluation and Validation of the nomogram}

In the analysis of specificity, we used both the receiver operating characteristic (ROC) curve and Brier score to evaluate the diagnostic value and accuracy of the nomogram model. With respect to the ROC curve, the nomogram model was greater than traditional TNM staging in the training cohort (1-year AUC: 0.747 vs. 0.641, 3-year AUC: 0.761 vs. 0.679, 5-year AUC: 0.759 vs. 0.682, 7-year AUC: 0.749 vs. 0.673, respectively, $P<0.001$, Fig. 3$)$. The Brier score is a measure of overall 
Table 2 Multivariate analysis for exploring potential risk factors for prognosis of AEG

\begin{tabular}{|c|c|c|c|c|c|}
\hline \multirow[t]{2}{*}{ Characteristics } & \multicolumn{2}{|c|}{ Initial multivariate model } & \multicolumn{3}{|c|}{ Final multivariate model } \\
\hline & SHR $(95 \% \mathrm{Cl})$ & $P$ & beta & SHR (95\% Cl) & $P$ \\
\hline \multicolumn{6}{|l|}{ Age (year) } \\
\hline$<60$ & Reference & & & Reference & \\
\hline$\geq 60$ & $1.393(1.223-1.588)$ & $<0.001$ & 0.329 & 1.389 (1.220-1.583) & $<0.001$ \\
\hline \multicolumn{6}{|l|}{ Tstage } \\
\hline $\mathrm{T} 1$ & Reference & & & Reference & \\
\hline $\mathrm{T} 2$ & $1.604(1.204-2.137)$ & $<0.001$ & 0.465 & $1.592(1.211-2.093)$ & $<0.001$ \\
\hline T3 & $2.207(1.698-2.869)$ & $<0.001$ & 0.773 & $2.167(1.710-2.747)$ & $<0.001$ \\
\hline $\mathrm{T} 4$ & $2.606(1.990-3.411)$ & $<0.001$ & 0.938 & $2.555(2.000-3.265)$ & $<0.001$ \\
\hline \multicolumn{6}{|l|}{ N stage } \\
\hline No & Reference & & & Reference & \\
\hline N1 & $1.831(1.525-2.198)$ & $<0.001$ & 0.596 & $1.814(1.515-2.172)$ & $<0.001$ \\
\hline N2 & $2.536(2.089-3.077)$ & $<0.001$ & 0.918 & $2.505(2.073-3.028)$ & $<0.001$ \\
\hline N3 & $3.417(2.750-4.247)$ & $<0.001$ & 1.205 & $3.335(2.702-4.116)$ & $<0.001$ \\
\hline \multicolumn{6}{|l|}{ Grade } \\
\hline Low grade & Reference & & & Reference & \\
\hline High grade & $1.277(1.120-1.457)$ & $<0.001$ & 0.248 & $1.281(1.124-1.460)$ & $<0.001$ \\
\hline \multicolumn{6}{|c|}{ Number of examined lymph nodes } \\
\hline$<5$ & Reference & & & Reference & \\
\hline$<10$ & $0.736(0.555-0.975)$ & 0.032 & -0.286 & $0.751(0.569-0.993)$ & 0.040 \\
\hline$<15$ & $0.630(0.477-0.832)$ & 0.001 & -0.455 & $0.635(0.481-0.838)$ & 0.013 \\
\hline$\geq 15$ & $0.535(0.410-0.698)$ & $<0.001$ & -0.616 & $0.540(0.414-0.704)$ & $<0.001$ \\
\hline \multicolumn{6}{|l|}{ Race } \\
\hline White & Reference & & & & \\
\hline Black & $0.973(0.713-1.329)$ & 0.860 & & & \\
\hline Others & $0.829(0.662-1.039)$ & 0.100 & & & \\
\hline \multicolumn{6}{|l|}{ Sex } \\
\hline Female & Reference & & & & \\
\hline Male & $0.965(0.825-1.129)$ & 0.660 & & & \\
\hline \multicolumn{6}{|l|}{ Size $(\mathrm{cm})$} \\
\hline$<1.0$ & Reference & & & & \\
\hline$<2.0$ & $1.179(0.732-1.899)$ & 0.500 & & & \\
\hline$<3.0$ & $1.087(0.682-1.731)$ & 0.730 & & & \\
\hline$<5.0$ & $1.121(0.707-1.777)$ & 0.630 & & & \\
\hline$\geq 5.0$ & $1.048(0.659-1.668)$ & 0.840 & & & \\
\hline
\end{tabular}

SHR sub-distribution hazard ratio, $\mathrm{Cl}$ confidential interval

performance and captures aspects of both calibration and discrimination. It is a representation of the difference between the predicted probability and the actual outcome. The score ranges from 0 to 1 , with values closer to 0 indicating better predictive ability. In terms of the Brier score, the accuracy of the nomogram was also better than traditional TNM stage at 3-year point (0.198 vs. $0.217, P=0.012)$, 5 -year point $(0.198$ vs. $0.216, P=0.008)$, and 7 -year point $(0.199$ vs. 0.215 , $P=0.014$ ) (Fig. 3). The calibration curves showed the dots close to a $45^{\circ}$ diagonal line, indicating that the nomogram were well calibrated (Fig. 4).

To further externally validate the nomogram, we used ROC curves and calibration curves to evaluate the prediction accuracy of the new model. The ROC curves presented a better diagnostic value than traditional TNM staging and the calibration curves presented an acceptable consistency between the model prediction and the actual observation for 1-, 3-, 5-, 7- and 10-year point (Fig. 5). 


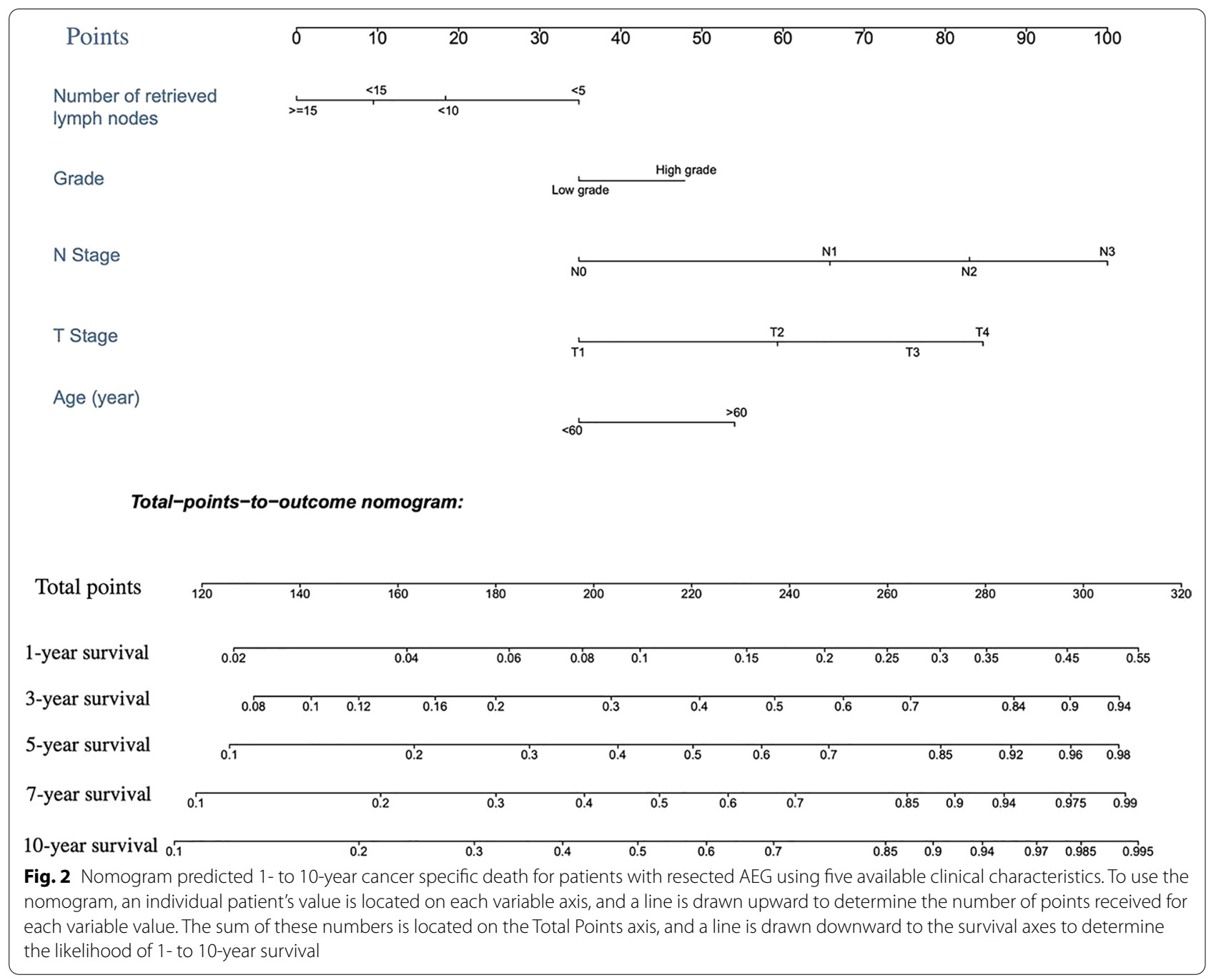

We then used DCA to compare the clinical usefulness of the nomogram and traditional TNM staging. By decision curve analysis, the nomogram was better than traditional TNM staging in clinical conditions (Fig. 6). Compared with traditional TNM staging, the nomogram showed a larger net benefit across the range of death risk in the analysis.

\section{Discussion}

As a junctional tumor type between the esophagus and stomach, the definition, evaluation, and management of AEG remains elusive. Based on the 8th AJCC TNM stage classification, AEG patients could receive better evaluation and management [18]. However, the new complex classification may sometimes confuse clinicians, resulting in unfavorable evaluation and therapy [6]. Ergo, a new specific evaluation and classification system for AEG is urgently needed. In this study, a new classification system was developed through the use of a competing risk model nomogram for predicting survival in patients with AEG. This nomogram is based on five variables: number of LNs examined, grade, invasion ( $\mathrm{T}$ stage), metastatic LNs ( $\mathrm{N}$ stage), and age. This nomogram produced more accurate predictions on the survival of patients than the pathologic 8th TNM classification and showed better clinical usefulness throughout the time during which patients were analyzed as assessed by DCA.

Due to the unique anatomic location, the AJCC classification of AEG remains a topic of debate in recent years. An accurate staging system is required for clinicians to choose the best follow-up treatment [19]. In the 8th edition of AJCC classification, more attention was paid to changes and developments leading to better clinical decision making and predictive accuracy. Separated staging of AEG reflects the individualized approach taken by AJCC. In the new AJCC staging system, a more complex 

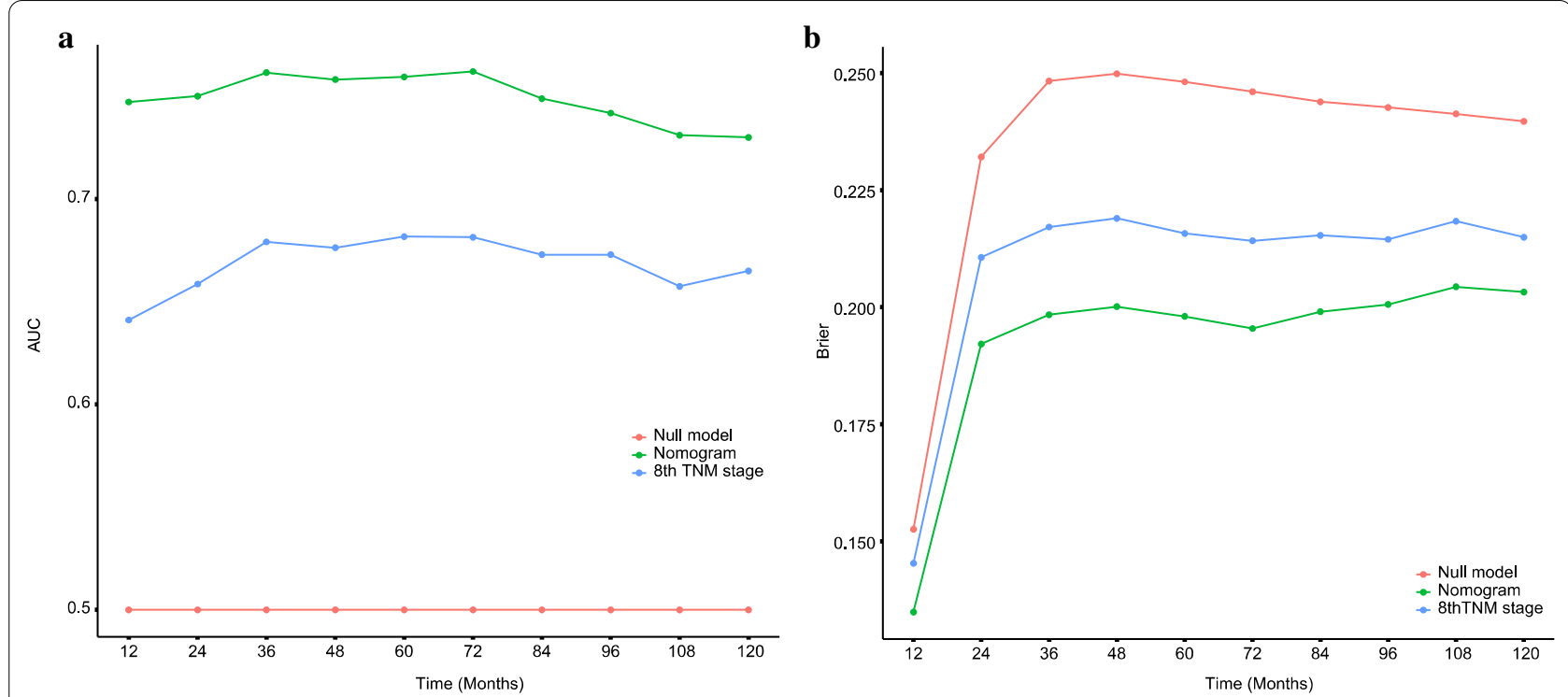

Fig. 3 AUC (a) and Brier score (b) of the Nomogram and 8th TNM Stage in prediction of prognosis of patients from 1-year to 10-year point. AUC: areas under the receiver operating characteristic curve

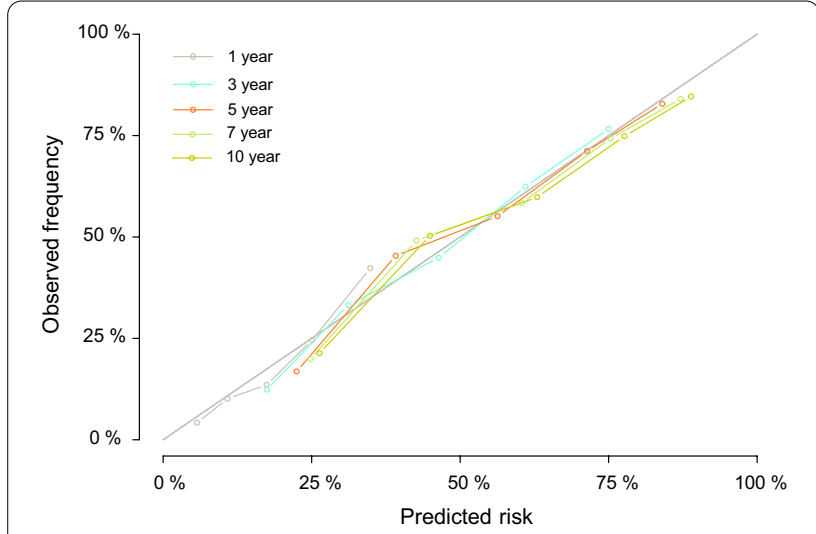

Fig. 4 The calibration curves for predicting patient survival of the training cohort at 1-, 3-, 5-year, 7-year, 10-year point. Nomogram-predicted cancer specific survival is plotted on the $x$-axis; actual cancer specific survival is plotted on the $y$-axis. A plot along the 45-degree line would indicate a perfect calibration model in which the predicted probabilities are identical to the actual outcomes

classification separated by 3 different groups was introduced, namely clinical (cTNM), pathologic (pTNM), and post-neoadjuvant pathologic (ypTNM) stage groups [18]. The clinical stage is defined using physical examination, endoscopy, and imaging examination, which shows big heterogeneity between different surgeons. In clinical practice, pathologic stage groups showed the most widely distributed survival [20,21]. In addition, a direct comparison of the different editions AJCC classification is possible only for pathologic staging. Therefore, we used the pathologic stage groups of the $8^{\text {th }}$ TNM staging method in our comparison.

Traditional TNM classification stratified the AEG into 3 grouping methods: the pathologic depth, number of metastatic LNs, and distant metastasis of the tumor. The survival data are usually accompanied by multiple outcomes, which may have a competitive association [10, $22,23]$, resulting in overestimation of the cumulative incidence. A nomogram is a well-analyzed statistic tool which provides a comprehensive probability of outcome [12]. A prior study comparing nomogram with $7^{\text {th }}$ AJCC classification, which included six clinical associated factors (age, sex, depth of invasion, metastasized LNs, examined LNs, histological grade), showed greater accuracy for the TNM classification [8]. In clinical practice, however, we found the outcome of AEG could be blocked by many other events $[5,24]$. Therefore, we used a new competing risk nomogram to reduce the influence of these outcomes $[25,26]$. In our study, we used the number of examined LNs, grade, $\mathrm{N}$ stage, $\mathrm{T}$ stage, and age as the classification factors, part of which is in consensus with the TNM stage system. This simple nomogram could eliminate possible influence from other lethal factors and be useful for clinicians in practice.

In our nomogram, the number of examined LNs was considered as another variable of evaluating the survival in addition to normal factors in the AJCC staging system. The number of examined LNs presented to be a protective factor $(<10,<15, \geq 15$, SHR 0.751, 0.635, 0.540, $P<0.001)$ in this nomogram, indicating that resection of more LNs leads to a better survival. Several trials also 

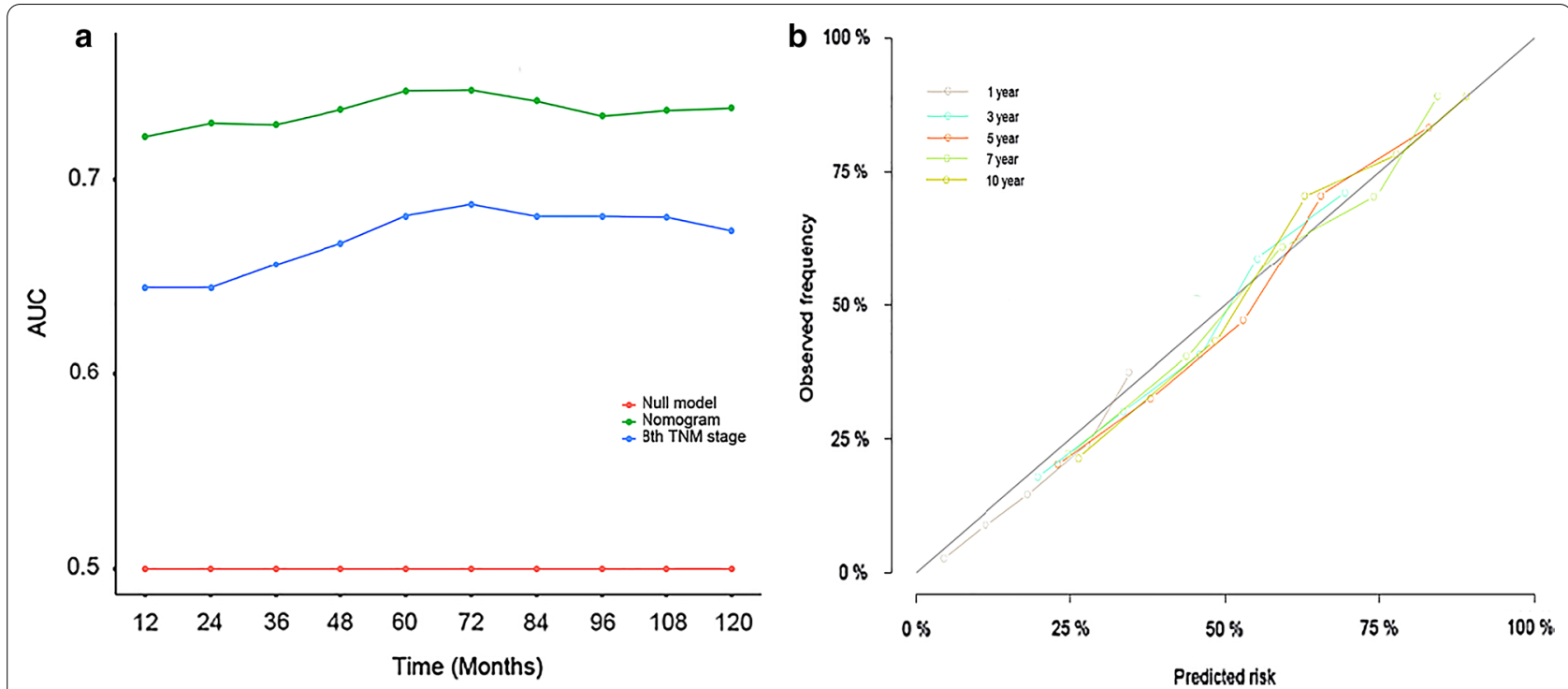

Fig. 5 a AUC of the Nomogram and 8th TNM Stage in prediction of prognosis of the validation cohort patients from 1-year to 10-year point. $\mathbf{b}$ The calibration curves for predicting patient survival of the validation cohort at 1-, 3-, 5-year, 7-year, 10-year point
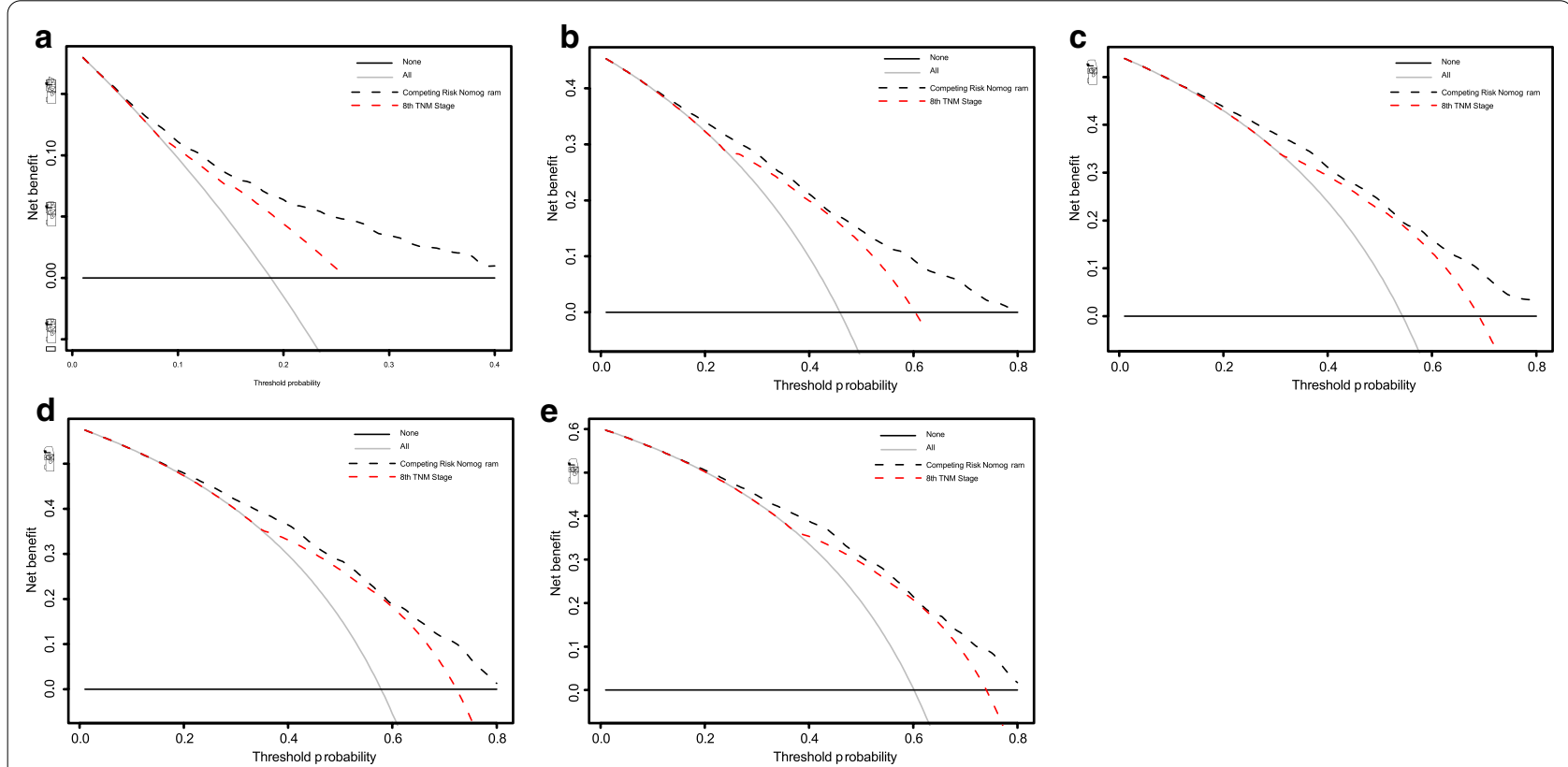

Fig. 6 Decision curve analysis for the Competing Risk Nomogram and the 8th TNM Stage in prediction of prognosis of patients at 1, 3, 5, 7, 10-year point

recommended the number of examined LNs as a great predicting factor in the staging system of AEG [27-29]. Different surgical methods may determine the number of LN examinations [30]. The choice of surgery depends on the type of AEG: with type I being treated as esophageal cancer, and type II and III regarded as gastric cancer [10,
30]. More examined LNs may represent a more exhaustive surgical dissection and less residing positive LNs. Moreover, not only could the dissection procedure of the surgeon affect the number of examined LNs, but so could the LN searching of the pathologist. Thus, we could 
mark the examined LNs as an evaluation for pathological credibility.

This work also has some limitations. Firstly, as cancer biology and validation of biologic factors has evolved, it has become more effective in predicting the outcome of cancer $[18,23]$. The $8^{\text {th }}$ AJCC classification recommended some of these factors, with strong evidence showing great accuracy in AEG. Due to the missing data from the SEER database, we were unable to make a full comparison to the whole $8^{\text {th }}$ classification; further study combining biologic data may lead to a more 'personalized' approach. Secondly, the SEER database is based on retrospective data collection, with diagnosis and surgery all depending on different doctors from several different medical centers. Moreover, the current work was also limited by the inability to involve some recognized prognostic factors such as Siewert type, surgical operation, radiation and chemotherapy due to lack of detailed information of therapy related variables in the SEER database. In addition, the missing data during collection caused many patients to be excluded, which might lead to skewed results.

\section{Conclusion}

We developed and validated a novel nomogram and risk stratification system integrating clinicopathological characteristics for AEG patients. The model showed superior prediction ability for AEG patients than traditional TNM classification.

\section{Abbreviations \\ AEG: Adenocarcinoma in the esophagogastric junction; TNM: Tumor-Node- Metastasis staging classification; AJCC: The American Joint Committee on Cancer; EGJ: Esophagogastric junction; LN: Lymph node; SEER: Surveillance, Epidemiology and End Results; SHR: Sub-distribution hazard ratio; AUC: Areas under receiver operating characteristic curves; DCA: Decision curve analysis; ROC: Receiver operating characteristic.}

\section{Acknowledgements}

We would like to thank Dr Shan Wu from Shanghai Six People's Hospital for her help in supporting the methodology of R language.

\section{Authors' contributions}

TW and YW substantially contributed to design of the study, analysis and interpretation of data and the drafting of the manuscript. DZ and YC substantially contributed to conception and design of the study. $\mathrm{HZ}, \mathrm{CW}$ and XZ substantially contributed to collection and assembly of data. All authors have contributed, read and approved the final manuscript.

\section{Funding}

This study received funding from the Special Research Projects for Capital Health Development (No. 2014-1-2151) and Beijing Hope Run Special Fund of Cancer Foundation of China (No. LC2017L01). The founders had no role in study design, data collection and analysis, decision to publish, or preparation of the manuscript.

\section{Availability of data and materials}

The datasets generated and analyzed during the current study are available in the SEER database (https://seer.cancer.gov/) and from the corresponding authors upon reasonable request.

\section{Ethics approval and consent to participate}

This study was approved by the Ethics Committee of the National Cancer Center/National Clinical Research Center for Cancer/Cancer Hospital, Chinese Academy of Medical Sciences and Peking Union Medical College (Beijing, China). The SEER database is publicly available and provides de-identified case data. Because of the analysis used anonymous clinical data, written informed consent from subjects was waived.

\section{Consent for publication}

Not applicable.

\section{Competing interests}

All authors declare no conflicts of interest related to this article.

\section{Author details}

${ }^{1}$ Department of Pancreatic and Gastric Surgical Oncology, National Cancer Center/National Clinical Research Center for Cancer/Cancer Hospital, Chinese Academy of Medical Sciences and Peking Union Medical College, No. 17 PanjiayuanNanli, Chaoyang District, Beijing 100021, China. ${ }^{2}$ Key Laboratory of Carcinogenesis and Translational Research (Ministry of Education), Department of Pathology, Peking University Cancer Hospital \& Institute, Beijing 100142, China.

Received: 12 March 2020 Accepted: 17 January 2021 Published online: 26 January 2021

\section{References}

1. Ferlay J, Parkin DM, Steliarova-Foucher E. Estimates of cancer incidence and mortality in Europe in 2008. Eur J Cancer. 2010;46(4):765-81.

2. Ferlay J, Soerjomataram I, Dikshit R, Eser S, Mathers C, Rebelo M, Parkin DM, Forman D, Bray F. Cancer incidence and mortality worldwide: sources, methods and major patterns in GLOBOCAN 2012. Int J Cancer. 2015;136(5):E359-386

3. Blot WJ, Devesa SS, Kneller RW, Fraumeni JF Jr. Rising incidence of adenocarcinoma of the esophagus and gastric cardia. JAMA. 1991;265(10):1287-9.

4. Kusano C, Gotoda T, Khor CJ, Katai H, Kato H, Taniguchi H, Shimoda T. Changing trends in the proportion of adenocarcinoma of the esophagogastric junction in a large tertiary referral center in Japan. J Gastroenterol Hepatol. 2008;23(11):1662-5.

5. Devesa SS, Blot WJ, Fraumeni JF Jr. Changing patterns in the incidence of esophageal and gastric carcinoma in the United States. Cancer. 1998;83(10):2049-53.

6. Rice TW, Gress DM, Patil DT, Hofstetter WL, Kelsen DP, Blackstone EH. Cancer of the esophagus and esophagogastric junction-Major changes in the American Joint Committee on Cancer eighth edition cancer staging manual. CA Cancer J Clin. 2017;67(4):304-17.

7. Suh YS, Lee KG, Oh SY, Kong SH, Lee HJ, Kim WH, Yang HK. Recurrence pattern and lymph node metastasis of adenocarcinoma at the Esophagogastric junction. Ann Surg Oncol. 2017;24(12):3631-9.

8. Zhou Z, Zhang H, Xu Z, Li W, Dang C, Song Y. Nomogram predicted survival of patients with adenocarcinoma of esophagogastric junction. World J Surg Oncol. 2015;13:197.

9. Lagarde SM, ten Kate FJ, Reitsma JB, Busch OR, van Lanschot JJ. Prognostic factors in adenocarcinoma of the esophagus or gastroesophageal junction. J Clin Oncol. 2006;24(26):4347-55.

10. Hasegawa S, Yoshikawa T. Adenocarcinoma of the esophagogastric junction: incidence, characteristics, and treatment strategies. Gastric Cancer. 2010;13(2):63-73.

11. Dignam JJ, Zhang $Q$, Kocherginsky $M$. The use and interpretation of competing risks regression models. Clin Cancer Res. 2012;18(8):2301-8.

12. lasonos A, Schrag D, Raj GV, Panageas KS. How to build and interpret a nomogram for cancer prognosis. J Clin Oncol. 2008;26(8):1364-70. 
13. Fine JP, Gray RJ. A proportional hazards model for the subdistribution of a competing risk. Publ Am Stat Assoc. 1999;94(446):496-509.

14. Hanley JA, MCNeil BJ. A method of comparing the areas under receiver operating characteristic curves derived from the same cases. Radiology. 1983;148(3):839-43.

15. Callegaro D, Miceli R, Bonvalot S, Ferguson P, Strauss DC, Levy A, Griffin A, Hayes AJ, Stacchiotti S, Pechoux CL, et al. Development and external validation of two nomograms to predict overall survival and occurrence of distant metastases in adults after surgical resection of localised softtissue sarcomas of the extremities: a retrospective analysis. Lancet Oncol. 2016;17(5):671-80.

16. Blanche P, Dartigues JF, Jacqmin-Gadda H. Estimating and comparing time-dependent areas under receiver operating characteristic curves for censored event times with competing risks. Stat Med. 2013;32(30):5381-97.

17. Wu S, Chen JN, Zhang QW, Tang CT, Zhang XT, Tang MY, Li XB, Ge ZZ. A New metastatic lymph node classification-based survival predicting model in patients with small bowel adenocarcinoma: a derivation and validation study. EBioMedicine. 2018;32:134-41.

18. Amin MB, Greene FL, Edge SB, Compton CC, Gershenwald JE, Brookland RK, Meyer L, Gress DM, Byrd DR, Winchester DP. The Eighth Edition AJCC Cancer Staging Manual: Continuing to build a bridge from a populationbased to a more "personalized" approach to cancer staging. CA Cancer J Clin. 2017;67(2):93-9.

19. Sobin LH. TNM: evolution and relation to other prognostic factors. Semin Surg Oncol. 2003;21(1):3-7.

20. Rice TW, Rusch VW, Apperson-Hansen C, Allen MS, Chen LQ, Hunter JG, Kesler KA, Law S, Lerut TE, Reed CE, et al. Worldwide esophageal cancer collaboration. Dis Esophagus. 2009;22(1):1-8.

21. Rice TW, Ishwaran H, Blackstone EH, Hofstetter WL, Kelsen DP, AppersonHansen C. Worldwide Esophageal Cancer Collaboration I: Recommendations for clinical staging (CTNM) of cancer of the esophagus and esophagogastric junction for the 8th edition AJCC/UICC staging manuals. Dis Esophagus. 2016;29(8):913-9.

22. lelpo B, Pernaute AS, Elia S, Buonomo OC, Valladares LD, Aguirre EP, Petrella G, Garcia AT. Impact of number and site of lymph node invasion on survival of adenocarcinoma of esophagogastric junction. Interact Cardiovasc Thorac Surg. 2010;10(5):704-8.
23. Siewert JR, Feith M, Stein HJ. Biologic and clinical variations of adenocarcinoma at the esophago-gastric junction: relevance of a topographicanatomic subclassification. J Surg Oncol 2005, 90(3):139-146; discussion 146.

24. Siegel RL, Miller KD, Jemal A. Cancer statistics, 2018. CA Cancer J Clin. 2018;68(1):7-30.

25. Li J, Li X, Gu J, Ma X, Xue F. A competing-risks nomogram for predicting probability of death from CRC in Chinese Han patients with Stage I-III CRC. Jpn J Clin Oncol. 2018:48(12):1088-95.

26. van Vugt JLA, Alferink LJM, Buettner S, Gaspersz MP, Bot D, Darwish Murad S, Feshtali S, van Ooijen PMA, Polak WG, Porte RJ, et al. A model including sarcopenia surpasses the MELD score in predicting waiting list mortality in cirrhotic liver transplant candidates: A competing risk analysis in a national cohort. J Hepatol. 2018;68(4):707-14.

27. Kang CH, Kim YT, Jeon SH, Sung SW, Kim JH. Lymphadenectomy extent is closely related to long-term survival in esophageal cancer. Eur J Cardiothorac Surg. 2007;31(2):154-60.

28. Boshier PR, Anderson O, Hanna GB. Transthoracic versus transhiatal esophagectomy for the treatment of esophagogastric cancer: a metaanalysis. Ann Surg. 2011;254(6):894-906.

29. Lagarde SM, Reitsma JB, Ten Kate FJ, Busch OR, Obertop H, Zwinderman $\mathrm{AH}$, Moons J, van Lanschot JJ, Lerut T. Predicting individual survival after potentially curative esophagectomy for adenocarcinoma of the esophagus or gastroesophageal junction. Ann Surg. 2008;248(6):1006-13.

30. Liu K, Feng F, Chen XZ, Zhou XY, Zhang JY, Chen XL, Zhang WH, Yang K, Zhang B, Zhang HW, et al. Comparison between gastric and esophageal classification system among adenocarcinomas of esophagogastric junction according to AJCC 8th edition: a retrospective observational study from two high-volume institutions in China. Gastric Cancer. 2019;22(3):506-17.

\section{Publisher's Note}

Springer Nature remains neutral with regard to jurisdictional claims in published maps and institutional affiliations.
Ready to submit your research? Choose BMC and benefit from:

- fast, convenient online submission

- thorough peer review by experienced researchers in your field

- rapid publication on acceptance

- support for research data, including large and complex data types

- gold Open Access which fosters wider collaboration and increased citations

- maximum visibility for your research: over 100M website views per year

At BMC, research is always in progress.

Learn more biomedcentral.com/submissions 